\title{
OBSERVATIONS ON THE CHEMISTRY OF THE WATERS OF THE BAY OF BENGAL OFF MADRAS CITY DURING 1948-1949
}

\author{
BY R. JAYARAMAN, M.A. \\ (Central Marine Fisheries Research Station, Mandapam Camp)
}

Received July 11, 1950

(Communicated by Dr. H. Srinivasa Rao, F.A.sc.)

\section{INTRODUCTORY}

THE study of the fundamental problem of the productivity of the sea involves a knowledge of the composition of the sea water, particularly with reference to those inorganic compounds which form a valuable link in the food chain of life in the sea. The most important among these are the compounds of phosphorus, nitrogen and silicon. Studies on the distribution and seasonal variation of these compounds, commonly referred to as 'nutrients', form an essential preliminary to a more detailed biological investigation of the sea. Much work on these lines has been done by several workers abroad (vide Harvey, 1945), but their investigations were mostly confined to the waters of the temperate and colder regions. We do not have much information regarding the chemical conditions of the waters around the Indian coasts. Except for the investigations of Sewell (1928-29), Thompson and Gilson (1937) and Bal et al. (1946), little systematic work appears to have been done in our waters.

The present work was undertaken as a preliminary survey of the waters of the Bay of Bengal in the vicinity of Madras. Studies were made on the distribution and seasonal variations in concentration of phosphates, nitrates, nitrites and silicates during a period of 17 months-March 1948 to the end of July 1949. Simultaneous observations were also made on the variations in the salinity and dissolved oxygen of sea water.

\section{Collection of Samples}

\section{EXPERIMENTAL}

Samples of sea water for analyses were collected from the surface twice a week in the early hours of the morning at a distance of about 3 miles offshore near the Marina Beach. Glass-stoppered Pyrex bottles, 600$1,000 \mathrm{ml}$. capacity were employed for samples intended for general analyses and special $200 \mathrm{ml}$. bottles for dissolved oxygen determinations. 
Observations on the Chemistry of the Waters of the Bay of Bengal 93 Analytical Procedure

Phosphates.-The estimation of phosphates was done by the ceruleomolybdate method of Denigés modified by Atkins (1923). Nessler cylinders were used and the comparison of colour was made in daylight. The values given have not been corrected for 'salt error'.

Nitrates.-Harvey's Reduced Strychnine method (1926, 1929) was employed with the following modifications: The time of reaction was reduced to 1 hour in the light of the suggestions by Riddell (1936) and Rochford (1946). In the place of the original undiluted reagent of Harvey's, one diluted in the proportion of 1 to 3 with nitrate-free sulphuric acid was made use of. The nitrate-free acid for the purpose was prepared by the method of Ramachandran (1948). The diluted reagent proved to be much more sensitive than the original one. The colour developed was estimated in a Hellige-Duboscq Colorimeter.

Nitrites.-The nitrites were estimated by the method of Griess-Ilosvay worked out in detail for sea water by Orr (1926), and modified later by Robinson and Thompson (1948).

Silicates.-The method of Diénert and Wandenbulcke (1923) as adopted by Atkins (1926) was used. The standard for colour comparison was a

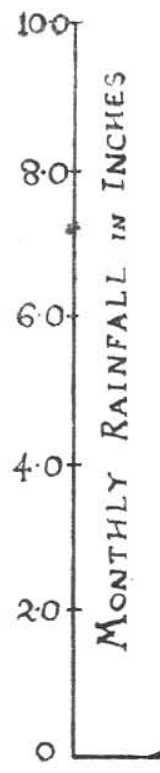

Mar apr May Jun Jul aug Sep Oct Nov Dec Jkin feb Mar apr May Jum Jul

FIG. 1. Showing the monthly rainfall in Madras City during the period 1948-49) From the Reports of the Regional Meteorological Centre, Madras). 


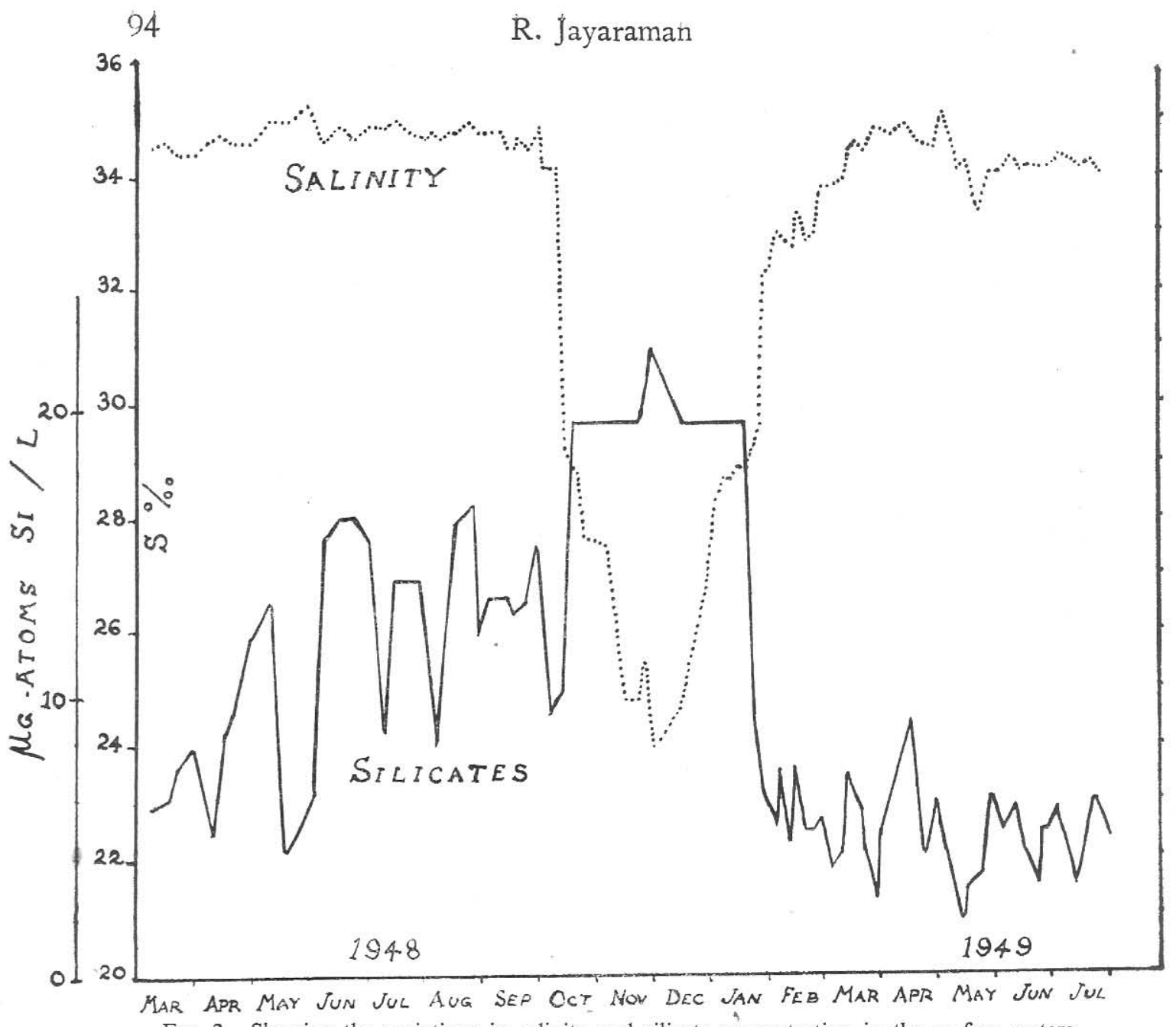

FIG. 2. Showing the variations in salinity and silicate concentration in the surface waters of the Bay of Bengal during the period 1948-49.

solution of potassium chromate buffered with borax as described by Thompson and Houlton (1933).

Oxygen.-The dissolved oxygen was estimated by the Winkler's method (Harvey, 1928).

Salinity.-The salinity determinations were done by the titration procedure of Oxner and Knudsen as described in detail by Harvey (1945). In the early part of the investigation the standard used was a solution of pure sodium chloride containing $32 \cdot 34 \mathrm{gm}$. of $\mathrm{NaCl}$ per litre and later Normal Sea Water of chlorinity, $19 \cdot 381 \%$, supplied by the Hydrographical Laboratories, Copenhagen, was used. 
Observations on the Chemistry of the Waters of the Bay of Bengal 95

\section{RESULTS}

The results obtained are shown graphically in Figs. 2, 3 and 4. The concentrations of the nutrients are expressed as microgram-atoms per litre following the international convention, and the oxygen content as $\mathrm{ml} / \mathrm{L}$. In Fig. 1 is represented the monthly rainfall for Madras for the period T948-49.

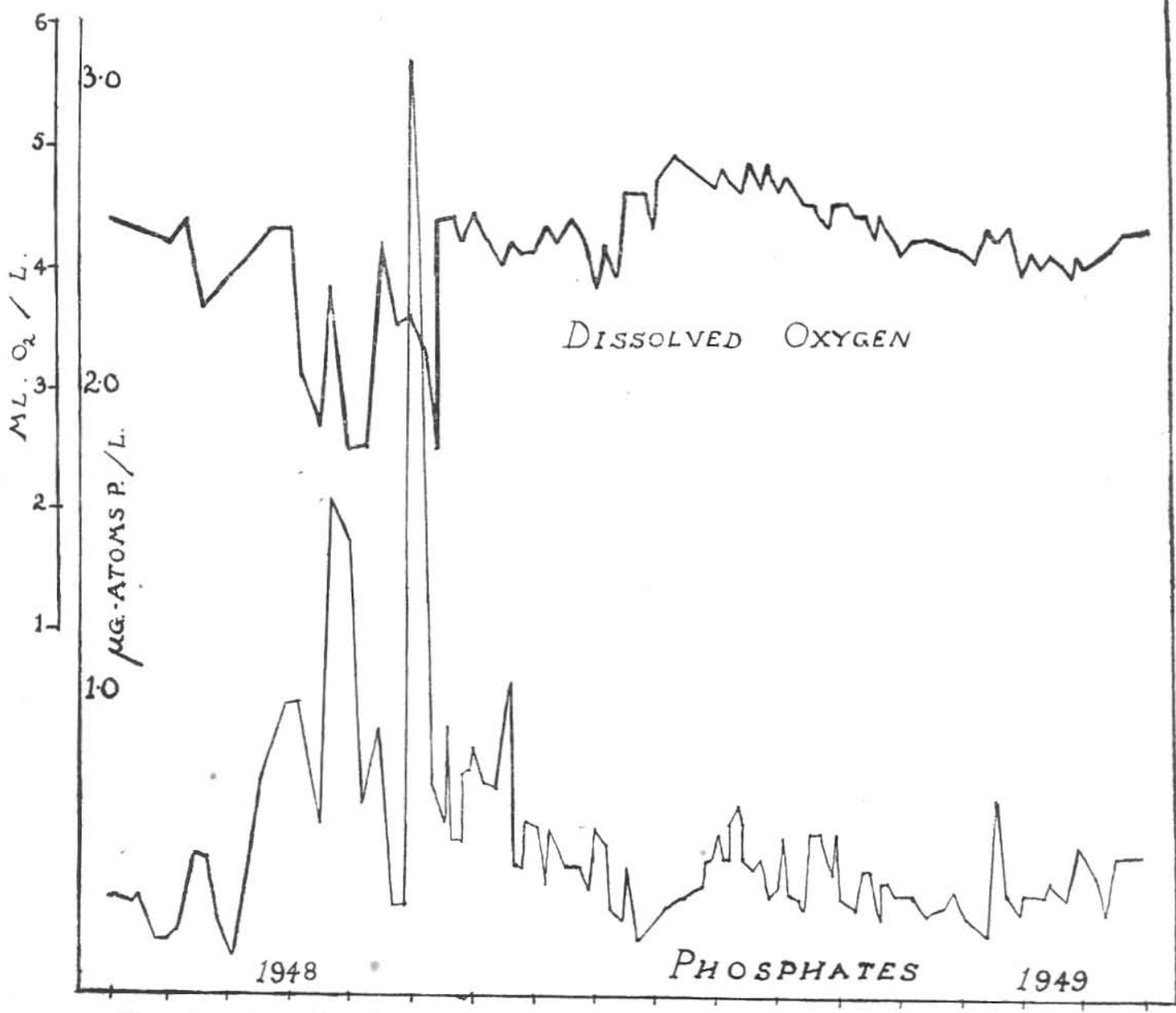

- Mur apr May Jun Jul aug sep oct nov dec Jan feb Mar apr May Jun Jul

FIG. 3. Showing the distribution of Phosphates and dissolved Oxygen in the surface waters of the Bay of Bengal during 1948-49, 


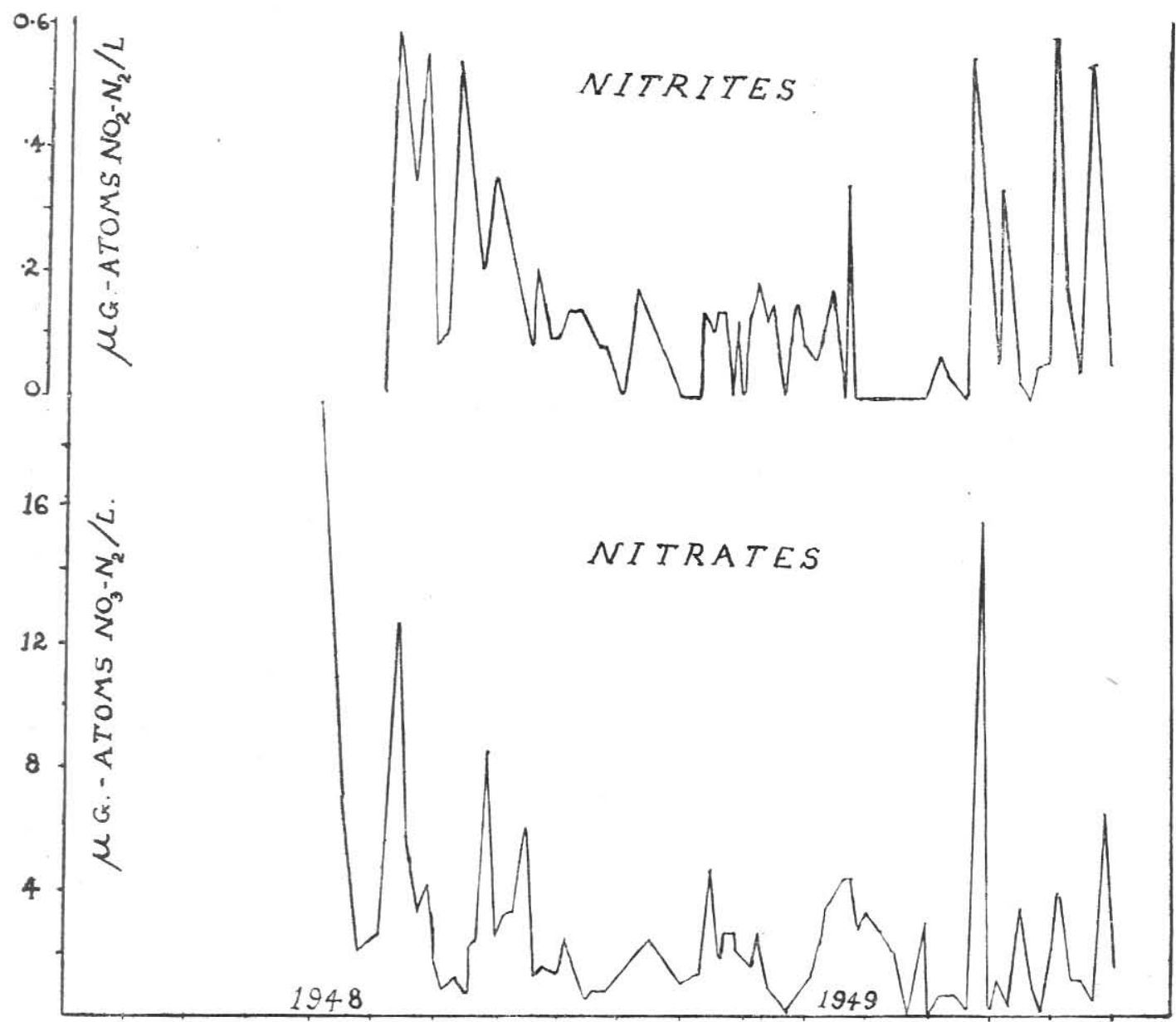

Mar Apr May Jun Jus Aug Sep oct Nov Dec Jan Feb Mar Apr May Jun Jul.

FIG. 4. Showing the nitrate and nitrite content of the surface waters of the Bay of Bengal during 1948-49.

\section{Discussion}

The data presented here show several interesting features. It would be proper to consider each of the constituents individually and indicate its relationship to the others.

Salinity.-The importance of salinity as an index of water movements is well known and data indicating the variations in salinity are useful in explaining the causes underlying the fluctuations in the nutrients and other constituents. The seasonal variations in salinity are shown in Fig. 2. It is seen that the salinity has been constant from March to the end of September 1948. By the middle of October, a downward trend is indicated and 
is continued till the end of December. A similar lowering in salinity in the surface waters of the Bay of Bengal at this part of the year has been recorded by Sewell (1928-29). It is seen from his charts that a strong southerly current runs along the east coast at this part of the year, carrying southwards " the low density waters from the mouth of the Godavari", and the lowering in salinity of the surface waters of the Bay may, therefore, be attributed to this influx of fresh water. A comparison of the rainfall data for Madras (Fig. 1) with the salinity shows that the lowering in salinity occurs at the period when the rainfall is at its maximum. It may, however, be pointed out the local rainfall alone could not have been responsible for the very low salinity noticed during the period; for it is to be observed that there is no appreciable lowering in salinity corresponding to the second peak - that is in the month of May, 1949-in the rainfall graph. Cooper (1933), too, has observed similar lowering in the salinity of the surface waters of the English Channel during certain months of the year, and he explaines it as being due to the pouring in of large volumes of fresh water from the rivers following heavy rains in the preceding months.

Phosphates.-The phosphate content of the surface waters of the Bay of Bengal is shown in Fig. 3. The highest concentrations are to be found in the months, May to September and the lowest from October to March. The seasonal fluctuations appear to be as marked as shown by other workers for the northern waters. Harvey $(1928,1930)$ has reported that phosphates in the surface waters of the English Channel show maximum concentrations during October to March and minimum during the rest of the year. It is of interest that lowest concentrations of phosphates are found in our waters from October to March. Dakin and Colefax (1935) have reported similar seasonal fluctuations in the southern hemisphere, but according to them, the average during the summer months is not appreciably less than during the winter months.

The seasonal decrease of phosphates in water due to the photosynthetic activity of the phytoplankton is well known from published data of different workers in many areas of the world. The values for dissolved oxygen is a fairly good index of the activity of the phytoplankton and a comparison of the graph (Fig. 3 top) representing the dissolved oxygen content with that representing phosphates (Fig. 3 bottom) shows that in the period in which the phosphates were maximum, the dissolved oxygen was at its lowest and vice versa.

Nitrates and Nitrites. - The distribution of nitrates and nitrites is shown in Fig. 4. The determination of these constituents could not be commenced earlier than July-August 1948 . 
An examination of the graph showing the distribution of nitrates reveals a close similarity to that of phosphates. The period of maximum concentration corresponds to that of phosphates. It is, however, seen that there is no constancy in the relative concentration of these two constituents, in other words, the $\mathrm{N} / \mathrm{P}$ ratio appears to be variable unlike what has been reported for oceanic waters. Redfield (1934) was the first to point out the quantitative relationship between nitrates and phosphates, and it has been further substantiated by Cooper (1937). The ratio of $15: 1$ for $\mathrm{N}: \mathrm{P}$ as arrived at by Cooper was, however, lower than that obtained by Redfield, but the values obtained by later workers were more in conformity with the observations of Cooper. It may be of interest to point out that in our waters the ratio of nitrate to phosphate has been consistently very low. It has been suggested by Riley (1941) from his investigations on the waters of the Georges Bank that such low values are characteristic of shallow regions, because the rapid return to the surface of the nutrients regenerated at the bottom leads to a preponderance of the more quickly regenerated phosphate. Moreover, as stated by Redfield (1934), the proximity of the land, the inflow of rivers and the peculiarities of the local flora and fauna may have a marked influence on the nitrate-phosphate relationship in our waters.

The nitrites show variations similar to the nitrates, the two curves being almost parallel to each other.

Silicates.-The silicate content of the surface waters during the period under study is represented in Fig. 2 along with the salinity. The distribution of this constituent appears to be influenced to a great extent by water movements. The southerly drift of fresh water which causes lowering of the surface salinity during the months October to December, brings about a rise in the concentration of silicates. It is well known that river waters are rich in silicates, and this increase in the silicate content could, therefore, be attributed to the influx of the river waters.

\section{SUMMARY}

Studies were made on the distribution and seasonal variation of salinity, dissolved oxygen and nutrients in the surface waters of the Bay of Bengal in the vicinity of Madras during 1948-49. The various constituents show marked seasonal fluctuations. The variations of phosphates and nitrates during the period appear to be more regular than those of silicates. The influx of fresh water at a certain season during the year is offered as an explanation for this phenomenon. 


\section{ACKNOWLEDGEMENTS}

The author wishes to express his sincere thanks to Dr. N. K. Panikkar for his valuable suggestions and to Dr. H. Srinivasa Rao, Chief Research Officer, Central Marine Fisheries Research Station, Mandapam Camp, for his kind permission to publish this paper.

\section{REFERENCES}

1. Atkins, W. R. G. $\quad$. J. Mar. Biol. Assn. U.K., 1923, 13, 119.

2. _— and Wilson, E. _. Biochem. Journ., 1926, 20, 1223.

3. Bal, D. V., Pradhan, L. B. Proc. Ind. Acad. Sci., 1946, 24B, (2), 60. and Gupte, K. G.

4. Cooper, L. H. N. $\quad$ _ J. Mar. Biol. Assn. U.K., 1933, 18, 677.

5.

.. Ibid., 1937, 22, 177.

6. Dakin, W. J. and Colefax, Proc. Linn. Soc. N.S.W., 1935, 60, 303. A. N.

7. Diènert, F. and Wanden- $\quad$ C. R. Acad. Sc., Paris, 1923, 176, 1478. bulcke, $\mathrm{P}$.

8. Harvey, H. W. _. J. Mar. Biol. Assn. U.K., 1926, 14, 71.

9.

.. Rapp. et Proc. Verb. Cons. perm. int. Explor. de la Mer., 1929, 53, 68.

10.

. Biological Chemistry and Physics of Sea Water, Cambridge Univ. Press, 1928.

11. Recent Advances in Chemistry and Biology of Sea Water, Cambridge Univ. Press, 1945.

12. Orr, A. P. . J. Mar. Biol. Assn. U.K., 1926, 14, 55.

13. Ramachandran, B. V.

. Nature, London, 1948, 162, 458.

14. Redfield, A. C.

. James Johnstone Memorial Volume, Univ. of Liverpool Press, 1934.

15. Riddell, W. A.

.. J. Biol. Canada, 1936, Bd. $2,1$.

16. Riley, G. A.

17. Rochford, D.

18. Robinson, R. J. and Thompson, T. G.

19. Sewell, R. B. S.

20. Thompson, E. F. and Gilson, H. C.

. Bull. Bingh. Oceanogr. Colln., 1941, 7, Art. 4.

. Austr. C.S. I. R. Bull., 1946, 220.

J. Mar. Res., 1948, 7, 42.

. Mem. Asiat. Soc. Bengal, 1928-29, 9, No. 5.

Sci. Rep. John Murray Expedn. (1933-34), 1933, 2, No. 2, 15-76.

21. Thompson, T. G. and Houlton, H. G. Ind. Eng. Chem., Anal. Edn., 1933, 5, 417. 